\title{
Resilience or Catastrophe? A possible state change for monarch butterflies in the West
}

\author{
Elizabeth Crone ${ }^{1}$ and Cheryl Schultz ${ }^{2}$ \\ ${ }^{1}$ Tufts University \\ ${ }^{2}$ Washington State University
}

February 23, 2021

\begin{abstract}
In the western United States, the population of migratory monarch butterflies is on the brink of collapse, having dropped from several million butterflies at coastal overwintering sites in the 1980's to about 2000 butterflies in the winter of 2020-21. At the same time, a resident (non-migratory) monarch butterfly population in urban gardens seems to be expanding northward. If anything, this urban population has been growing in recent years. We explore the meaning of these changes. The new resident population is not sufficient to make up for the loss of the migratory population; there are still orders of magnitude fewer butterflies now than in the recent past. The resident population also probably lacks the demographic capacity to expand its range inland during summer months, due to higher levels of infection by a protozoan parasite, and subsequently lower survival and fecundity. Nonetheless, the resident population may have the capacity to persist. This sudden change emphasizes the extent to which environmental change can have unexpected consequences. It also demonstrates how quickly these changes can happen. We hope it will provoke discussion about how we define resilience and viability in changing environments.
\end{abstract}

\section{Introduction}

Ecological dynamics are often surprising (Doak et al. 2008). By now, many ecologists have realized that some unlikely events are likely to happen (Pielke and Conant 2003), and that systems might suddenly shift between alternate stable states (Beisner et al. 2003). Many examples of such shifts come from aquatic systems (Carpenter 2005, Petraitis and Dudgeon 2015), and examples from terrestrial systems are mostly focused on community and ecosystem level processes (e.g., Suding et al. 2004). In fisheries, large transitions in abundance have been driven by life history shifts (Persson et al. 2007). However, there are few examples of terrestrial populations that have made sudden shifts from abundance to near collapse in a few years. Thus, the operating paradigm in management of at-risk species - at least in terrestrial systems - is that declines in abundance will occur at a pace for which conservation biologists and managers have time to assess a species' status and make recovery decisions over the course of processes that take years to implement.

Here, we explore sudden and dramatic changes in the abundance, distribution, and demography of monarch butterflies in the western USA. Rather than waiting for complete understanding, we describe these startling changes as they are occurring. We use simple calculations and available data to put these changes in the context of what we know about the current and likely future status of this population. We hope to inspire discussion about how we define population viability, and how we use ecology to guide management in the face of biological uncertainty.

\section{State of the monarch butterflies in the West}

Until now, monarch butterflies bred in North America west of the Rocky Mountains during the summer (Figure 1A). In fall, these western monarchs would migrate to the California coast and spend the winter clustering in a partly-dormant state in groves of pine and eucalyptus trees. In the $20^{\text {th }}$ century, millions of 
monarch butterflies clustered in these overwintering groves. However, by the 2010's the number of overwintering butterflies in the West had dropped from millions to two or three hundred thousand (Schultz et al. 2017). In 2018 and 2019, this number dropped to about thirty thousand (Pelton et al. 2019). In the fall of 2020, only about two thousand butterflies showed up (Xerces Society 2021). These declines have been attributed to degradation of wintering groves and summer breeding habitat, expansion of pesticide use and interacting effects of climate warming (Pelton et al. 2019, Crone et al 2020). Although monarch butterfly migration persists east of the Rocky Mountains, the phenomenon of monarch migration is on the brink of disappearing from the West (Figure 1B).

At the same time, monarch butterflies are abundant in gardens in cities on the California coast. No one has been counting these urban butterflies, but people living in coastal cities say they may be getting more abundant through time. One rough measure of a non-migratory urban population is reports of monarch breeding in summer near the coast, which have increased dramatically in recent years (Figure 1C, Supplemental analysis S1). This number is not a perfect estimate of the urban monarch butterfly population for example, it could mean that more people on the coast have become interested in reporting butterflies but it is generally consistent with the notion that monarch butterflies are becoming year-round residents in coastal cities, at the same time as the migratory population is disappearing.

\section{Can new residents replace old migrants?}

One of the most obvious first questions is whether the increase in resident monarch butterflies can replace the decline in the migratory population. To get a more quantitative estimate of the number of monarch butterflies in urban gardens, we surveyed their density in gardens in Berkeley, CA (Supplement S2). If we scale this estimate to all of northern and central California, there would be ${ }^{\sim 12,000}$ butterflies in urban gardens. This is less than $1 \%$ of the number of migratory monarch butterflies that overwintered in this part of California in the $20^{\text {th }}$ century. Furthermore, at most about $5 \%$ of monarch butterflies survive migration (Supplement S3). Therefore, at the peak of their summer breeding, there were probably at least 20 times as many monarch butterflies throughout the western states as we see in the overwintering groves. In other words, even if we added these urban monarch butterflies to our overwintering counts, and even if we have underestimated the abundance of urban monarch butterflies by an order of magnitude, we still have far fewer monarch butterflies in the West now than we did three or four years ago.

Another possibility is that the monarch butterfly populations from these urban gardens could themselves be a source of butterflies that would colonize the western states during summer. Again, it seems unlikely. Resident populations of monarch butterflies build up high levels of a protozoan parasite, Ophryocystis elektroscirrha (OE). In California, about $8 \%$ of migratory monarch butterflies are infected with OE, compared to about $75 \%$ of residents (Satterfield et al. 2016). Uninfected monarch butterflies have a tremendous capacity for population increase - a single female monarch can produce 12 adult daughters if milkweed host plants are not limiting (Flockhart et al. 2015) and perhaps 3 or 4 daughters under realistic conditions (Supplement S4, Figure 2). This capacity allows monarch butterfly populations to increase rapidly in size during the summer breeding generations. OE-infected monarch butterflies experience lower survival, lower egg-laying rates, and produce about 0.8 adult daughters per female (Supplement S4). If $75 \%$ of monarch butterflies have OE, the average rate of increase $(0.75 \times 0.8+0.25 \times 3)$ is about 1.35 adult daughters per female. This rate of increase is enough for resident monarch butterfly populations to persist in urban areas, but it does not give them the ability to rapidly colonize the other western states. Furthermore, traits associated with migration can evolve rapidly in monarch butterflies (Freedman et al. 2020, Tenger-Trolander et al. 2019). To date, no one has looked for such changes in resident California populations, but they could lose the genetic tendency to migrate, as well as the demographic capacity to do so.

\section{How do resident and migrant populations interact?}

In responding to the current status of western monarch butterflies, one of the greatest uncertainties is how much the resident and migratory populations interact. It may be that the growth of the resident population is independent of the collapse of the migratory one. Monarch butterflies have numerous resident populations 
worldwide, as well as the migratory ones in North America (Freedman et al. 2020). It could be that climate is becoming suitable for monarchs to live year-round in northern California. It could also be that urban monarch butterfly populations are growing because more people are planting milkweed in their yards, especially tropical milkweed (Asclepias currasavaca). Tropical milkweed is a popular horticultural plant, native to South America, that provides year-round food for monarch butterflies.

Alternatively, resident and migratory populations could be demographically connected. Perhaps migratory populations are declining because some individuals are attracted to the urban gardens in Fall, instead of migrating to coastal overwintering groves. Perhaps gardens are attractive stopping places in Spring, essentially absorbing butterflies that could have begun recolonizing inland sites. If our estimates of population growth rates or infection rates are just a little bit off, then the resident population may be a demographic sink (sensu Dias 1996), in the sense of being sustained only by immigration from the migratory population. In that case, we would expect declines in the migratory population to be followed within a few years by the loss of the resident population.

If populations do interact, a second concern is that the presence of an OE-infected resident population may increase parasite levels in the migratory population. OE is transmitted horizontally on milkweed leaves, and tropical milkweed does not die back in winter. In other parts of the southern United States, migratory monarch butterflies accumulate higher parasite loads when they interact with resident populations on tropical milkweed (Satterfield et al. 2018, Majewska et al. 2019). The potential transmission of OE from resident to migratory monarch butterflies creates a huge source of uncertainty. If the western monarch migration is on the point of collapse, it seems sensible to keep as many individual butterflies alive as possible, including the ones in gardens. However, increasing survival of infected monarch butterflies in gardens could increase parasite transmission to the migratory population (see Ezenwa and Jolles 2015 for a similar example in a mammal population). For monarch butterflies in California, this kind of negative interaction is possible but by no means certain. It may be that helping monarch butterflies in urban gardens is in fact the very best way to sustain monarch butterflies in the West during this critical time. We simply don't know.

\section{Resilience or catastrophe?}

From a conservation perspective, the change in western monarch butterflies presents a conundrum. Even knowing how to implement the precautionary principle of "Do no harm" is not obvious. On one hand, the benefits of milkweed in urban gardens - to public outreach and potentially to the monarch population - are large. On the other hand - if diseased monarchs from urban gardens significantly reduce the likelihood of a robust migration - then there might be real harm.

On the positive side, the appearance of this urban population is a promising sign of how resilient the species might be. In northern California, monarch butterflies have reinvented themselves. To residents of coastal California cities, it must seem like a success to be seeing monarch butterflies in their gardens on a regular basis. It is likely - though not guaranteed - that western monarchs will persist in a small portion of their historic range, even if they are lost from most of it. And yet even this positive note is tinged by the knowledge that we are losing something incredible. The overwintering clusters that used to occur in California are a spectacular phenomenon, and we may completely lose monarch butterflies from the interior West.

Perhaps the most striking feature of these changes is how quickly they happened. It has only been about five years since we (Schultz et al. 2017) published our first analyses of declines in overwintering populations of migratory monarch butterflies in the West. The subsequent drops by two more orders or magnitude happened in less than three years. By the time we resolve enough uncertainty to provide clear management guidelines, the system may have shifted again. When Doak et al. (2008) concluded that surprises are common in ecology, most of the examples they pointed to were small-scale surprises in experiments, and often on time scales that aligned much more with the time scales of research or management. One lesson from western monarchs is that, in this rapidly changing world, we should expect some species to change quickly and in completely unexpected ways.

\section{Conclusions}


In the West, the migratory population of monarch butterflies is collapsing. Based on available information, a new resident population seems to be expanding in urban gardens. Our assessment is that the resident population is much smaller and is unlikely to replace the migratory one. One could assume that the resident population is a conservation success or, alternatively, a cause of the decline of monarch migration in the West. In fact, we do not know if either of these is true. This startling transition emphasizes the general need to be prepared to rapidly reorient conservation policies and practices in changing environments.

\section{Acknowledgements}

We are grateful to S. Altizer, C. Edwards, D. James, and N. Warchola for allowing us to reinterpret data from their past and ongoing research in support of this essay, and to M. Power for comments on an early version of this essay. K. Dooley participated in three surveys. Our ideas have benefitted from conversations with the community of biologists and policy-makers working with monarch butterflies. Both authors acknowledge support from NSF DEB 19-20834 and DOD SERDP RC-2700.

\section{References}

Altizer, S.M. \& Oberhauser, K.S. (1999). Effects of the protozoan parasite Ophryocystis elektroscirrha on the fitness of monarch butterflies (Danaus plexippus ). Journal of invertebrate pathology , 74, 76-88.

Beisner, B.E., Haydon, D.T. \& Cuddington, K. (2003). Alternative stable states in ecology. Frontiers in Ecology and the Environment , 1, 376-382.

Carpenter, S.R. (2005). Eutrophication of aquatic ecosystems: bistability and soil phosphorus. Proceedings of the National Academy of Sciences , 102,10002-10005.

Crone, E.E., Pelton, E.M., Brown, L.M., Thomas, C.C. \& Schultz, C.B. (2019). Why are monarch butterflies declining in the West? Understanding the importance of multiple correlated drivers. Ecological Applications , 29, e01975

Dias, P.C. (1996). Sources and sinks in population biology. Trends in Ecology E Evolution, 11, 326-330.

Doak DF, Estes JA, Halpern BS, Jacob U, Lindberg DR, Lovvorn J, Monson DH, Tinker MT, Williams TM, Wootton JT, Carroll I, Emmerson, M., Micheli, F \& Novak. M. (2008) Understanding and predicting ecological dynamics: are major surprises inevitable. Ecology 89, 952-61.

Ezenwa, V.O. and Jolles, A.E. (2015). Opposite effects of anthelmintic treatment on microbial infection at individual versus population scales.Science 347,175-177.

Flockhart, D.T., Pichancourt, J.B., Norris, D.R. \& Martin, T.G. (2015). Unravelling the annual cycle in a migratory animal: breeding-season habitat loss drives population declines of monarch butterflies. Journal of Animal Ecology, 84,155-165.

Freedman, M.G., Dingle, H., Strauss, S.Y. \& Ramírez, S.R. (2020). Two centuries of monarch butterfly collections reveal contrasting effects of range expansion and migration loss on wing traits. Proceedings of the National Academy of Sciences, 117,28887-28893.

Majewska, A.A., Satterfield, D.A., Harrison, R.B., Altizer, S. \& Hepinstall-Cymerman, J. (2019). Urbanization predicts infection risk by a protozoan parasite in non-migratory populations of monarch butterflies from the southern coastal US and Hawaii. Landscape Ecology , 34, 649-661.

Pelton, E.M., Schultz, C.B., Jepsen, S.J., Black, S.H. \&Crone, E.E. (2019). Western monarch population plummets: status, probable causes, and recommended conservation actions. Frontiers in Ecology and Evolution 7,258 .

Persson, L., Amundsen, P.A., De Roos, A.M., Klemetsen, A., Knudsen, R. \& Primicerio, R. (2007). Culling prey promotes predator recovery - alternative states in a whole-lake experiment.Science , 316, pp.1743-1746. 
Petraitis, P.S. \& Dudgeon, S.R. (2015). Variation in recruitment and the establishment of alternative community states. Ecology, 96, 3186-3196.

Pielke Jr, R.A. \& Conant, R.T. (2003). Best practices in prediction for decision-making: lessons from the atmospheric and earth sciences.Ecology , 84, 1351-1358.

Satterfield, D.A., Villablanca, F.X., Maerz, J.C. \& Altizer, S. (2016). Migratory monarchs wintering in California experience low infection risk compared to monarchs breeding year-round on non-native milkweed.Integrative and Comparative Biology, 56,343-352.

Satterfield, D.A., Maerz, J.C., Hunter, M.D., Flockhart, D.T., Hobson, K.A., Norris, D.R. et al. (2018). Migratory monarchs that encounter resident monarchs show life-history differences and higher rates of parasite infection. Ecology Letters, 21, 1670-1680.

Schultz, C.B., Brown, L.M., Pelton, E. \& Crone, E.E. (2017). Citizen science monitoring demonstrates dramatic declines of monarch butterflies in western North America. Biological Conservation, 214,343-346.

Suding, K.N., Gross, K.L. \& Houseman, G.R. (2004). Alternative states and positive feedbacks in restoration ecology. Trends in Ecology \& Evolution, 19,46-53.

Tenger-Trolander, A., Lu, W., Noyes, M. \& Kronforst, M.R. (2019). Contemporary loss of migration in monarch butterflies. Proceedings of the National Academy of Science, 116, 14671-14676.

Xerces Society 2021. Western Monarch Thanksgiving Count Data, 1997-2020. Available at www.westernmonarchcount.org. Accessed 23 January 2021

\section{Figure Legends}

Figure 1. Change in status of western monarch butterflies. (A.) Breeding, overwintering, and resident range of western monarch butterflies in the Western USA. (B.) Trends in the migratory population through time, based on historical records and the Western Monarch Thanksgiving Count. The black line shows estimates from a state-space population viability analysis (PVA; Schultz \& Crone 2017) with $95 \%$ confidence intervals. The orange stars are raw counts from the Western Monarch Thanksgiving count, showing the steep decline in recent years. (C.) Increase of sightings of immature monarch butterflies (eggs, larvae, and pupae) near the coast, as a rough indicator of increasing abundance of a resident urban population of monarch butterflies. Point area is proportional to the number of sightings during each time period. The black line shows predictions from analyses of year-round breeding, shown for summer months (June-August) because migratory monarch butterflies do not breed in winter, with confidence intervals in gray. The estimate of 12,000 urban butterflies comes from ground surveys in 2020-21. See further details in supplement S1 (analyses of sighting records) and S2 (estimating the resident population size). The photo is of a monarch butterfly caterpillar on tropical milkweed in a garden in San Luis Obispo, CA (photo credit: Nancy Starry).

Figure 2. Effects of infection by the protozoan parasiteOphryocystis elektroscirrha (OE) on monarch butterfly rates of increase during breeding generations. Black lines indicate estimated growth rates (see Supplement S4), with $95 \%$ confidence intervals in gray. Points represent values for the estimated proportion of OE-infected monarch butterflies in migratory and resident populations (from Satterfield et al. 2018). Dotted lines identify (1) the minimum growth rate for persistence, set at exact replacement (growth rate of 1 per generation), and (2) an estimate of the minimum growth rate for range expansion during breeding season (3-fold increase per generation). The range expansion minimum is a rough estimate, justified in at least two ways: First, migratory monarch butterflies have low survival during fall migration, on the order of 2-5\% (Supplement S3). If a population increases 3-fold per generation for four breeding generations, the resulting 27 -fold increase approximately balances migration mortality. Second, the land area of core western states (California, Nevada, Idaho, Oregon, and Washington) is about 527,733 square miles (136,682,847 Ha). If a population starts at 1,000,000 overwintering butterflies (a reasonable historic estimate) and increases to $27,000,000$, there would be $\sim 1$ monarch butterfly per $5 \mathrm{Ha}$ in its breeding range, which is broadly consistent 
with its former status as a common species. The photo is of an OE-infected monarch butterfly emerging in the lab (photo credit: Christopher Jason, Washington State University).

Figure 1.
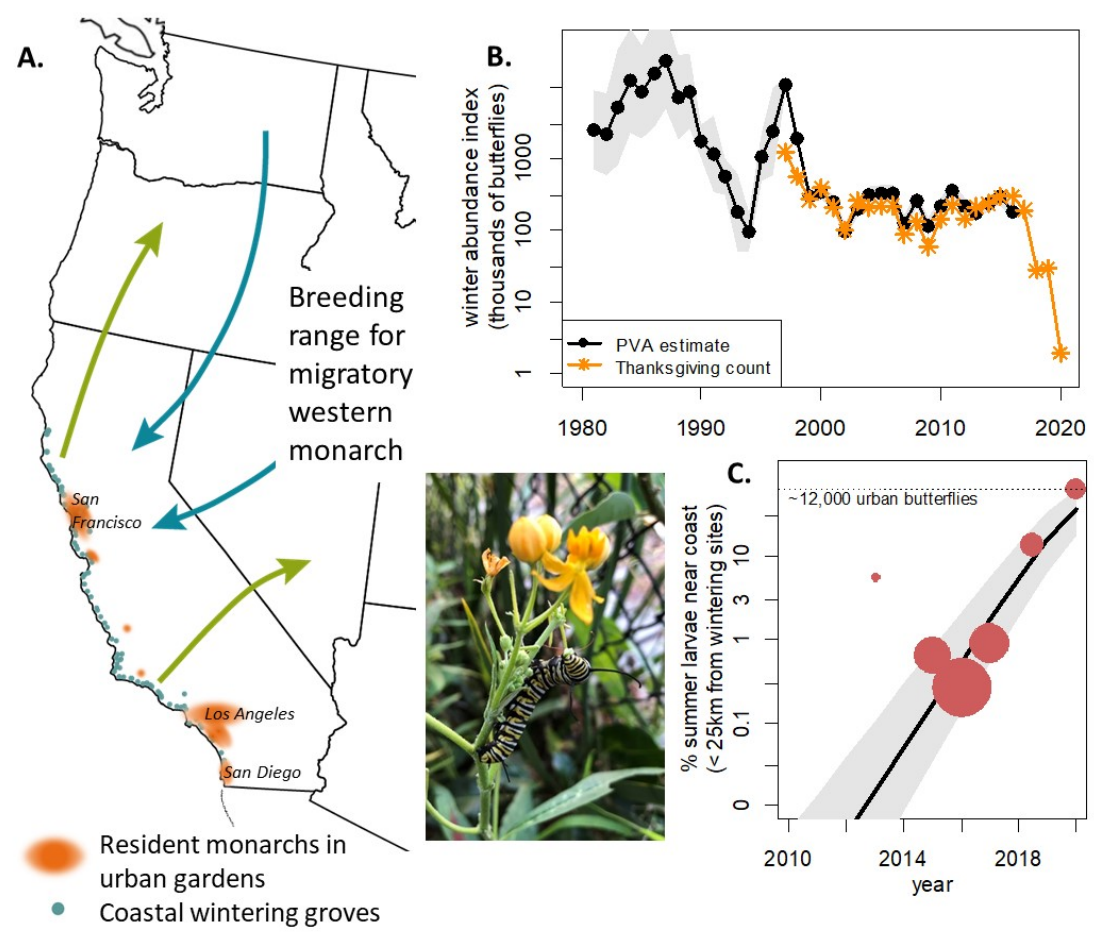

Figure 2
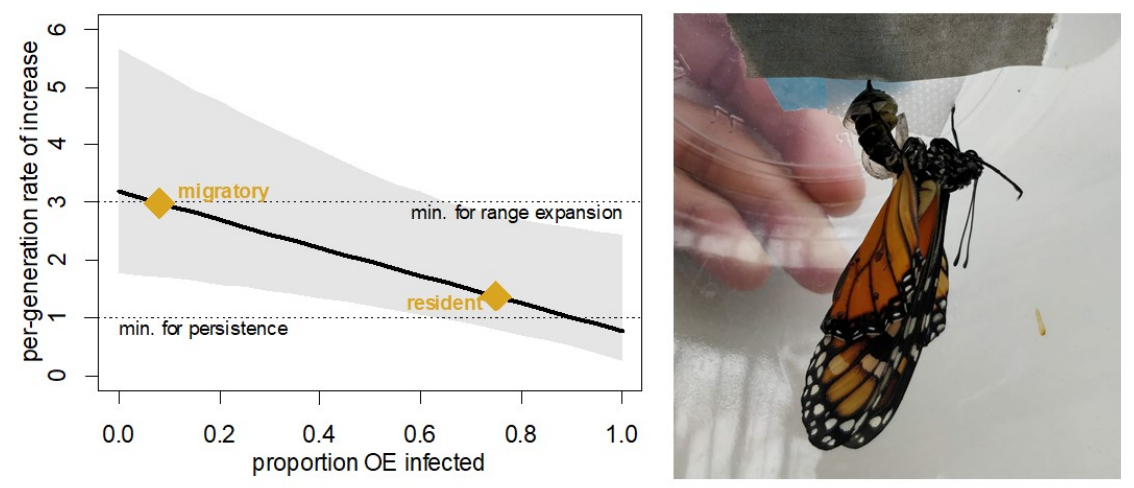